Wider consultation at an earlier stage of the project's development, perhaps with senior management and marketing departments, might have prevented many of the problems encountered such as the non-recognition of the legal issues surrounding use of pharmacy premises and the adverse publicity attendant on the launch of the service. This adverse publicity may have led to the retailer withdrawing from the partnership but thankfully overall had no impact on sales within the store. On reflection, this publicity led to an increased public awareness of the service and we therefore had no need to try and obtain more funding for further publicity.

The failure to consult more widely in the initial planning phase could have had serious legal consequences. The service would have been operating outside the law had the need to deregulate a room not been recognised in time.

The start of the service could have been delayed had the Pharmaceutical Society not reacted promptly to the pharmacist's request for deregulation. An alternative would have been to issue prescriptions to clients in place of medication, adding significantly to the costs of the service. In future, if such initiatives are planned, consideration must be given to their impact on other agencies and the contribution that these agencies could impart to the success of them. In this instance the partners only considered their own organisations, without thinking through the implications of using pharmacy premises. In anticipation of public interest in such an innovative service, a press launch was arranged immediately prior to its commencement to which all major news agencies were invited. No one attended the press launch, although two Scottish daily newspapers published the issued press release on the day of the launch. The storm of adverse publicity and press furore that subsequently ensued had not been anticipated by any of the partners. The staff involved was put under significant strain. In future any similar service should plan for such an eventuality by ensuring that senior management and marketing departments take a proactive approach. More involvement and discussion with national media through the appropriate organisational departments might have mitigated the publicity that surrounded the launch of this initiative. A common approach to press and interested members of the public was negotiated between the partners in response to this.

All those who took part in the interviews identified the same common aims for the clinic that are vital for any interagency initiative to function successfully. The informality of the partnership arrangements has worked well in this instance, with no formal contact between partner organisations. This may reflect the degree of agreement between the partner organisations about the project aims. More formal arrangements may be required in other partnerships settings; however, in the absence of any other similar projects we are only able to offer our own experience as guidance in this area.

Statements on funding and competing interests

Funding. None identified.

Competing interests. None identified.

References

1 The Scottish Needs Assessment Programme. Teenage pregnancy in Scotland. Glasgow: Scottish Forum for Public Health Medicine, 1994. 2 Information and Statistics Division (ISD) of the Common Services Agency for the Scottish Health Service. Teenage pregnancy in Scotland, 1989-1998. Health Briefing, 99/04: 1-8, 1999.

3 Morrison A, Mackie CM, Elliot L, et al. The Sexual Health Help Centre: a service for young people. J Pub Health Med 1997; 19: $457-463$.

4 The Scottish Office. Towards a healthier Scotland. Edinburgh: The Stationary Office, 1999

5 Bloxham S. The contribution of interagency collaboration to the promotion of young people's sexual health. Health Educ Res 1997; 12: 91-101.

6 Peak GL, McKinney DL. Reproductive and sexual health at the school based/school-linked health centre: an analysis of services provided by 180 clinics. J Adolesc Health 1996; 19: 276-281.

7 The National Health Service (NHS) (Scotland) Act 1978, Section 9, as amended by the National Health Service and Community Care Act 1990.

8 The National Health Service (NHS) (Pharmaceutical Services) (Scotland) Regulations 1995 Schedule 1(5).

9 Shucksmith J. Hendry LB. Young people's perceptions of their own health needs: a report of a project funded for the Health Education Board for Scotland. Edinburgh: Health Education Board for Scotland, 1996.

10 Milburn K. Peer education, young people and sexual health: a critical review. Edinburgh: Health Education Board for Scotland, 1996.

11 Press release. The Daily Mail, Tuesday 1st December 1998; 1.

12 Press release. The Daily Mail, Friday 5th December 1998; 17

13 Press release. The Evening Times, Monday 30th November 1998; 14

14 Press release. The Evening Times, Thursday 28th October 1999; 1.

\title{
Evaluation of a young person's sexual health service in a commercial setting
}

K F McAllister, MRCOG, DFFP, Consultant in Family Planning and Reproductive Health Care, The Sandyford Initiative, Glasgow, UK; L Elliott, MSc, Senior Health Promotion Officer, Greater Glasgow Health Board, Glasgow, UK; D A M Thomson, BSc Pharm, MR Pharm, Primary Care Services Manager, Boots the Chemist, Glasgow, UK; A Bigrigg, MRCOG, MFFP, Clinical Director, The Sandyford Initiative, Glasgow, UK; C M Mackie, MFFP, SCMO, Family Planning and Reproductive Health Care, The Sandyford Initiative, Glasgow, UK

Correspondence: Dr K F McAllister, The Sandyford Initiative, 6 Sandyford Place, Sauchiehall Street, Glasgow G3 7NB, UK. Tel: +44 (0) 141211 8130.Fax: +44 (0) 141211 8139.E-mail: Kay.McAllister@glacomenscot.nhs.uk

(Accepted $5^{\text {th }}$ July 2002)

The Journal of Family Planning and Reproductive Health Care 2002: 28(4): 203-205

\section{Abstract}

Objective. To determine the acceptability and accessibility of a sexual health service for young people in a city centre pharmacy.
Design. Prospective qualitative survey of clients attending a new sexual health service, including client characteristics and semi-structured interviews.

Participants. Clients attending the service between January and May 1999. 
Main outcome measures. Social demographics, reasons for attendance and consultation outcomes for clients together with their views of the service.

Results. A total of 98 clients (average of three clients per session) attended from January to May 1999, ranging from 14 to 39 years of age. Clients came from 41 postcode areas of the city (which has over 80 postcode areas) and neighbouring districts, covering all social strata. Only four clients had never been sexually active; 53 clients attended for emergency contraception, with 26 attending for hormonal contraception. A total of $93 \%$ of those asked were either satisfied or very satisfied with the opening times. All clients were satisfied or very satisfied with the clinic location.

Conclusions. The setting of a sexual health service for young people in a city centre pharmacy allows access from a wide area. The timing and location of the service were the most commonly quoted reasons for attendance. All clients were asked to participate in a semi-structured interview, unless the interviewer was already engaged; results were obtained for 66 clients (67\% of attendees).

\section{Key message points}

- Sexual health services for young people involving public/private collaboration improve accessibility and acceptability.

- Services outside a traditional medical setting are highly acceptable to young people.

- Alternative service provision for sexual health can attract clients who would not approach routine services.

\section{Introduction}

Teenage pregnancy rates in the UK are the highest in Western Europe and have long been recognised as a cause for concern. ${ }^{1}$ Scottish conception rates (1988 figures), despite being slightly lower than those in England, are still high at 67.6 per 1000 in 16-19-year-olds and 8.4 per 1000 in 13-15-year-olds. ${ }^{2}$ In Glasgow a sexual health service specifically for young people was launched in 1995. Extensive research of this and other young people's services highlight the many factors influencing young people's uptake of services. These included opening times, location and staff attitudes and approach. ${ }^{3-6}$ It was recognised that to improve young people's uptake of sexual health services, radical changes in service delivery were needed ${ }^{7}$ such as offering services on Sunday afternoons and Thursday evenings (coinciding with extended shopping hours). ${ }^{8}$ These services might benefit from being located in alternative venues where better anonymity could be afforded. A recent paper also demonstrated the effects that health professionals can have in influencing teenage pregnancy rates. ${ }^{9}$

As a result of these findings a service was established in a Glasgow city centre pharmacy in 1998. The clinic was held in a room normally used as an office during the day, with direct access onto the shop floor. It was staffed at an information point on the shop floor by a family planning trained nurse or a health promotion officer. A doctor was present in the consultation office at every clinic.

\section{Participants and methods}

Information was collected from all 98 clients attending the service between January and May 1999. This included age, resident postcode, employment status, reason for attendance, previous sexual experience including condom use, previous use of sexual health services, alternative services considered and consultation outcome and future anticipated service use.

Independent researchers from the Health Promotion Department of Greater Glasgow Health Board undertook semi-structured interviews between February and April 1999. Clients were approached following their consultation and asked if they would participate. ${ }^{10}$ Only one researcher was present at each session therefore clients leaving whilst the researcher was engaged were not approached. Interview results were obtained from 66/98 clients.

\section{Results}

All 98 clients were female; many attended with friends or partners. Of these, $19(20 \%)$ were aged 16 years or under, $38(39 \%)$ were age 17 to 20 years old and $22(22 \%)$ were age 21 to 25 years. The age range was 14-39 years with a mean average of 20.5 years.

Clients came from 41 different postcode areas of Glasgow and its surroundings, with an even distribution. There was failure to record the postcode area of one client. Twenty-one clients $(21 \%)$ were still at school and $22(22 \%)$ were in further education. Forty-nine clients were in employment $(50 \%)$ and five $(5 \%)$ were unemployed. Status was not recorded for one client.

Thirty-two clients had previously attended their general practitioner (GP) for contraceptive services, 28 had attended an established family planning clinic and nine clients attended this new service on more than one occasion. For 29 clients (30\%) this was the first ever contact with a contraceptive advice service. Clients were asked at the start of their consultation the main reason for attending. These reasons are listed in Table 1, together with the consultation outcome.

Table 1 Summary of the reasons for attending the new sexual health service and the outcome of the consultations

\begin{tabular}{lll}
\hline Reasons for attending & Clients (n) & $\begin{array}{l}\text { Clients with this } \\
\text { outcome (n) }\end{array}$ \\
\hline Advice only & 11 & 15 \\
Condoms & 6 & 8 \\
Emergency contraception & 53 & 48 \\
First supply COC & 11 & 13 \\
First supply POP & 2 & 1 \\
First supply Depo-Provera & 0 & 1 \\
Repeat supply COC & 11 & 12 \\
Repeat supply POP & 1 & 0 \\
Repeat supply Depo-Provera & 1 & 2 \\
\hline
\end{tabular}

COC, Combined oral contraceptive; POP, progestogen-only pill.

A total of $94 / 98$ clients $(96 \%)$ were already sexually active. Condoms were always used by 44 clients, with a further 42 clients using them sometimes and eight never using them.

Clients were asked where they would have attended had this new service not been available; 28 would have attended their GP, 53 an established family planning clinic, three an accident and emergency (A\&E) department and 14 none at all. In the future, 37 individuals planned to return to this service, whilst 52 planned to return to their previous service provider. Further referral was necessary for two clients, as there were no facilities for examination in the pharmacy premises. 


\section{Semi-structured interviews}

\section{Location}

Of the 66 clients who were interviewed no one was unhappy with the location of the service; $85 \%$ were very satisfied and $15 \%$ were satisfied. Some typical responses were: 'It's really easy to get to. There is a train station and because it's the St Enoch's Centre, everyone knows where it is.' and 'It's central. It's easier transport-wise'.

\section{Service timing}

Most clients were satisfied (49\%) or very satisfied (44\%) with the opening times. Clients were also asked if they would have preferred an alternative service time. Of the $7 \%$ dissatisfied with the current opening times, Saturday afternoon was the most popular alternative (4/6 respondents). Typical responses were: 'It's the only one open on a Sunday and I think a lot of people would be frantic if this wasn't open.' 'Good to keep the Thursday and Sunday opening times but it would be good to have one on Saturday.'

\section{Future service requirements}

Thirty-seven $(38 \%)$ clients planned to use this service in future, with $23(23 \%)$ returning to their GP, $23(23 \%)$ to the central family planning service and six $(6 \%)$ to local clinics. Nine clients $(9 \%)$ were unsure. However, all 66 clients interviewed would be happy to return to the new clinic if necessary.

\section{Overall impressions}

All clients found the service to be similar or better than existing alternatives with a more relaxed and informal atmosphere. It was pleasing to note that they acknowledged the standard of care and professionalism of staff was not compromised by this informality. "Very good, professional, open-minded, non-judgmental' and 'relaxed and easy to talk to' were typical of the comments made.

Clients were asked whether they would recommend this service to any friends and all but one stated that they would. This client felt that she could not discuss the topic with friends. Reasons such as 'handy in town, people are not afraid to go into a chemist', 'reliable, in confidence, not intimidating' were given for this recommendation. Overall, perhaps the most significant factor influencing the use of this service is the greater anonymity afforded. As one client remarked: 'You could be coming here for anything'.

\section{Discussion}

The need for separate sexual health services has been highlighted by many government reports over the past 5 years, such as the Scottish Needs Assessment Programme and Towards a healthier Scotland. ${ }^{11,12}$

The Social Exclusion Unit for England and Wales in its report on teenage pregnancies has specifically mentioned the need for services that are more accessible to teenagers and those of school age in particular. ${ }^{13}$ It has also been suggested that teenagers are more likely to access services if they are within a short bus ride or walk away. ${ }^{14,15}$ Using a busy, well-known, city centre premises close to bus and train stations was felt to be more easily accessible than existing clinic premises ${ }^{7}$ and, due to the alternative nature of the premises, would offer more anonymity for the clients. This was borne out by the higher proportion of under 16year-olds attending this service compared to the young people's service at the central clinic $(11.5 \%$ vs $20 \%)$. These points were spontaneously mentioned to the researchers by many of the clients. Although overall numbers in the present study are small, the study findings suggest that any new service, which manages to reach young people and make contraception, safer sex and health education freely available in an inner city area, must break down barriers, lessen restrictive practices and improve health.

Providing a service on Sundays will certainly improve access, extending the hours available that are suitable for young people. Those at school often have difficulty accessing evening services when some explanation to their parents for their absence is required. Many young people in full-time education undertake Saturday employment making attendance on this particular day difficult. The initial number of clients attending the service was perhaps lower than we would have liked. However, these numbers are probably typical for the inception of such a service and may be because young people discover the existence of services through chatting to friends rather than through formal advertising. 8,16,17 Over the same 5-month period a year later, 405 people accessed the service, demonstrating the time it takes for such a service to become established. Client attendance has stabilised at this level since then. Much of the adverse publicity and demonstrations from pressure groups would suggest that provision of sexual health services to young people encourages promiscuity. It is therefore interesting to note that in the present study almost all the clients were sexually active prior to their attendance (94/98). Only 13 clients were commenced on regular hormonal contraception with almost half given emergency contraception (48/98). Fourteen clients would not have accessed any other existing service and it is perhaps these young women who are most at risk of an unwanted pregnancy. ${ }^{18}$ Now that emergency contraception is available as an 'over the counter' preparation, the service may see more clients who have received emergency contraception from the pharmacy and subsequently require long-term contraception. The inevitable cost of this from pharmacies may be prohibitive for many young people, who will continue to access this service for free medication.

Over the period of the research the only males seen by medical staff were those accompanying their partner. It may be because young men often view sexual health services are being specifically for women. ${ }^{19}$ It was encouraging to note that men did stop at the information point within the store for advice leaflets. This confirms our need to find different approaches for young men who wish to obtain advice, e.g. more male staff on duty or different venues for men such as football or rugby grounds.

This project has proven to be a positive step towards the provision of young people's sexual health care. Hopefully, further projects similar to this, taking sexual health care 'to the high street', will help to reduce the number of unplanned pregnancies in teenagers.

Statements on funding and competing interests

Funding. None identified.

Competing interests. None identified.

References

1 Secretary of State for Health. The health of the nation: a strategy for health in England. London: Her Majesty's Stationery Office, 1992.

2 Information and Statistics Division (ISD) of the Common Services Agency for the Scottish Health Service. Teenage pregnancy in Scotland, 1989-1998. Health Briefing, 99/04: 1-8, 1999.

3 Morrison A, Mackie CM, Elliot L, et al. The Sexual Health Help Centre: a service for young people. J Pub Health Med 1997; 19: $457-463$.

4 Health Services Manager. Family planning and abortion services for young people. London: Department of Health and Social Security, HC (84)34, 1984.

5 Goudie H, Redman J. Making health services more accessible to younger people. Nurs Times 1996: 92(24): 45-46. 
6 Department of Health and Social Security. Health Services Development: Planning Guidelines 1998-1991. London: Department of Health and Social Security, HC (88)43, 1991.

7 Malcolm J. Contraception services for teenagers: The experience of the Brook Advisory Centre in Scotland. J Adolesc Health Welfare 1988; 1: 6-7.

8 Allen I. Family planning and pregnancy counselling projects for young people. London: Policy Studies Institute, 1991.

9 Hippisley-Cox J, Allen I, Pringle M, et al. Association between teenage pregnancy rates and the age and sex of general practitioners: cross sectional survey in Trent 1994-7. BMJ 2000; 320: 842-845.

10 Helzner JF. Toward a client orientation in family planning. Int Fam Plan Persp 1993; 19: 31-33.

11 Scottish Needs Assessment Programme. Teenage pregnancy in Scotland. Glasgow: Scottish Forum for Public Health Medicine, 1994.

12 The Scottish Office. Towards a healthier Scotland. Edinburgh: The Stationery Office, 1999.
13 The Stationery Office. Teenage pregnancy: report by the Social Exclusion Unit 1999. London: The Stationery Office, 1999.

14 Clements S, Stone N, Diamond I, et al. Modelling the spatial distribution of teenage conception rates within Wessex. $\mathrm{Br} J$ Fam Plann 1985; 11: 44-49.

15 Scally G, Hadley A. Accessibility of sexual health services for young people: survey of clinics in a region. J Manag Med 1995; 9(4): 51-52.

16 McAvoy BR. Communication skills and family planning doctors. $\mathrm{Br} J$ Fam Plann 1985; 11: 44-49.

17 Hill MR. Do family planning facilities meet the needs of the sexually active teenager? Br J Fam Plann 1987; 13: 143-151.

18 Todd J, Currie C, Smith R. Health behaviour of Scottish school children: technical report 2. Sexual health in the 1990s. Edinburgh: University of Edinburgh, 1999.

19 Davidson N. Oh boys! Sex education and young men. Health Educ 1996; 3: 20-23

\section{The Janssen-Cilag Travelling Scholarship}

This scholarship, established in memory of Dr Ann Horler, continues to be sponsored by Janssen-Cilag. The purpose of the scholarship is to enable the successful candidate to travel to any country, subject to approval by the selection committee, in order to gain experience that will be applicable to his or her daily work. Those eligible to apply are current Diplomates and Members of the Faculty of Family Planning and Reproductive Health Care of the Royal College of Obstetricians and Gynaecologists, who are based in the British Isles and currently working in family planning

Once the successful scholar is announced at the AGM usually held in May, Janssen-Cilag will arrange presentation of the sponsorship, the value of which has increased to $\mathbf{2 5 0 0}$, enabling the scholar to make his or her own travelling arrangements. It is expected that the successful candidate will travel before March of the following year and give a report to the annual symposium of the Faculty in that year. This report may be published at a later date in the Journal of Family Planning and Reproductive Health Care. Those wishing to apply for the scholarship are asked to submit a typewritten summary of the proposed project, to include:

- Details of the places, organisations and individuals to be visited, with dates;

- Aims, objectives, benefits and how the experience will assist them in their daily work on their return; and

- A brief curriculum vitae with details of their current post.

Applications should be signed and dated, and returned to the Secretary, Faculty of Family Planning and Reproductive Health Care, 19 Cornwall Terrace, London NW1 4QP, UK by 7 April annually.

\section{The David Bromham Annual Memorial Award DYNAMIC DOCTORS DESERVE RECOGNITION}

David Bromham was the first Chairman of The Faculty of Family Planning and Reproductive Health Care. Sadly, halfway through his second term of office he became ill and in 1996 he died. His loss was tragic, not only for the Faculty, but for the family planning movement in Britain and worldwide.

Through his life David was an energetic and inspirational man. Whilst in Leeds he set up an assisted conception programme which was and is one of the most successful in the world. In 1991 he set up a fertility control unit designed to provide a more accessible service for the termination of pregnancy. He also carried out an extensive programme of research and was closely involved with The British Journal of Family Planning (now The Journal of Family Planning and Reproductive Health Care).

\section{The David Bromham Memorial Award}

David Bromham would have said: "Just do it! You have an idea? Follow it up. Keep it simple, don't worry if it fails. Any and every effort aids progress." Although David was a man of action he also knew how difficult it is to make time to further a project in the middle of a busy life. Dynamic doctors therefore deserve recognition.

\section{Award Criteria}

The David Bromham Memorial Award is in remembrance of a man who was happiest when deeply immersed in all that was happening within his fields of interest and who never wasted any time.

The Award is not intended to be a prize for a long and distinguished service, rather for a piece of work which through inspiration, innovation or energy has furthered the practice of family planning and reproductive health care in any way and any setting. It is not a research grant. Younger health professionals sometimes undervalue their achievements but they are exactly the people that David Bromham would have wished to see encouraged as this award now acknowledges.

\section{Nominations}

The award will be made either to an individual (who must be a current Diplomate or Member of the Faculty), or to a team that could be multidisciplinary. In the latter case the lead doctor should be a current member of the Faculty. You may nominate yourself or your team or be nominated by someone else.

\section{Award}

The award itself, which will be presented at each year's AGM, will comprise a monetary sum and inscribed memento.

\section{Sponsors}

The award is sponsored by the Pharmaceutical Contraceptive Group and its member companies: Hoechst Marion Roussel, JanssenCilag, Organon Laboratories, Pharmacia \& Upjohn, Schering Health Care and Wyeth Laboratories, with contributions from the members of the Faculty, affiliated groups and other organisations with which David had links.

\section{Nomination process}

Nomination is by completion of a form that can be downloaded from the Faculty website at www.ffprhc.org.uk. Completed submissions must be received at the Faculty office by 10 April annually. 